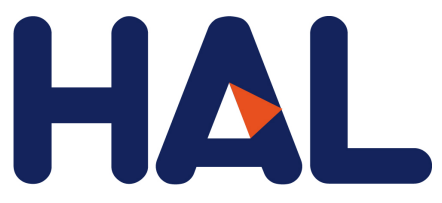

archives-ouvertes

\title{
Brief report: How many dimensions in the prosocial behavior scale? Psychometric investigation in French-speaking adolescents
}

\author{
Alexia Carrizales, Cyrille Perchec, Lyda Lannegrand-Willems
}

\section{To cite this version:}

Alexia Carrizales, Cyrille Perchec, Lyda Lannegrand-Willems. Brief report: How many dimensions in the prosocial behavior scale? Psychometric investigation in French-speaking adolescents. European Journal of Developmental Psychology, Taylor \& Francis (Routledge), 2017, 16 (3), pp.340-348. 10.1080/17405629.2017.1419952 . hal-02290920

\section{HAL Id: hal-02290920 \\ https://hal.archives-ouvertes.fr/hal-02290920}

Submitted on 18 Sep 2019

HAL is a multi-disciplinary open access archive for the deposit and dissemination of scientific research documents, whether they are published or not. The documents may come from teaching and research institutions in France or abroad, or from public or private research centers.
L'archive ouverte pluridisciplinaire $\mathbf{H A L}$, est destinée au dépôt et à la diffusion de documents scientifiques de niveau recherche, publiés ou non, émanant des établissements d'enseignement et de recherche français ou étrangers, des laboratoires publics ou privés. 


\title{
Brief report: How many dimensions in the prosocial behavior scale? Psychometric investigation in French- speaking adolescents
}

\author{
Alexia Carrizales (D), Cyrille Perchec and Lyda Lannegrand-Willems \\ Bordeaux University, Bordeaux, France
}

\begin{abstract}
The purpose of the study was to evaluate the factor structure and the reliability of the Prosocial Behavior Scale (PBS). To our knowledge, no factorial validity of the multifactorial structure of PBS has been published to date. The psychometric characteristics of the PBS were examined in several samples of French adolescents (aged 11-19, N1 = 1141, N2 = 1071, and N3 = 1640) using Confirmatory factor analyses (CFA). The original four-factor structure was not confirmed due to lack of discriminant validity. CFA led us to retain a two-factor solution with a good fit and a satisfactory reliability. Furthermore, the results support the convergent validity of the PBS: helping and caring dimensions were positively correlated with empathy. In addition, partial measurement invariance across gender and grade was attested. In conclusion, the results indicate that the French version of the PBS is a useful instrument for the assessment of prosocial behaviors in adolescence.
\end{abstract}

\section{ARTICLE HISTORY Received 7 August 2017; Accepted 4 December 2017}

KEYWORDS Prosocial behavior; adolescence; confirmatory factor analysis; measurement invariance

Research on the development and correlates of prosocial behaviors (i.e., behaviors intended to benefit others) has been an active field of study for the last three decades. Prosocial behaviors have been theoretically and empirically linked to a variety of positive cognitive, socioemotional and psychological outcomes for personal and social adjustment during adolescence (Alessandri et al., 2014; Gregory, Light-Häusermann, Rijsdijk, \& Eley, 2009). Although the importance of understanding behaviors that benefit society has been highlighted, surprisingly few measures are available, and none in French for evaluating prosocial behaviors.

While some measures do exist, they are typically characterized by a conceptualization of prosocial behaviors as a unidimensional global construct (Ladd \&

CONTACT Alexia Carrizales alexia.carrizales@u-bordeaux.fr

(-7) The supplemental data for this article is available online at https://doi.org/10.1080/17405629.2017. 1419952. 
Profilet, 1996; Rushton, Chrisjohn, \& Fekken, 1981). However, the developmental literature has shown different types of prosocial behaviors to be associated differently with other psychological constructs (Batson, 1998; Padilla-Walker $\&$ Carlo, 2014). For example, prosocialness is primarily expressed in the actions of helping, sharing, taking care of, and feeling empathic with others. Caprara, Steca, Zelli, and Capanna (2005) proposed a new scale for measuring these four behavioral expressions of prosocialness. Its properties were examined using an item response theory (IRT) approach. Specifically, unidimensional IRT models were used; hence, the multifactorial structure was not tested. To our knowledge, the factorial validity of the multifactorial structure has not been assessed to date. Moreover, it has mainly been used with late adolescents and emerging adults (college students). However, from early - middle to late adolescence, we consider that the socialization experiences and cognitive abilities may lead to changes in the internalization of culturally related values and in prosocial behaviors (Calderón-Tena, Knight, \& Carlo, 2011). Therefore, studies focusing on early-to-late adolescence should be conducted.

The aim of our study was to investigate whether the factor structure of the Prosocial Behaviors Scale (PBS) identified by Caprara and colleagues (2005) in adults would be the same in a French sample of early and late adolescents. To this end, we proceeded by translating and assessing the factorial validity, reliability, convergent validity (with empathy), and measurement invariance of the French PBS.

\section{Method}

\section{Participants}

Three independent samples were used for the analyses, Sample 1 ( $N=1141$, $\left.M_{\text {age }}=14.35, \mathrm{SD}=1.69\right)$ and Sample $2\left(N=1071, M_{\text {age }}=15.19, \mathrm{SD}=2.27\right)$ used in the EFA analyses and Sample $3\left(N=1640, M_{\text {age }}=14.58, S D=1.88\right)$ used in the CFA analyses. Specifically, participants from Sample 3 came from an ongoing longitudinal study. They were divided into two groups based on educational grade. The first one included 867 junior high school adolescents (grade 6-9, 51\% females, $M_{\text {age }}=13.11 ; S D=1.17$ ) and the second one included 773 high school adolescents (grade $10-12,43 \%$ females, $M_{\text {age }}=16.22 ; \mathrm{SD}=.93$ ). The data are a nationally representative sample of adolescents in Secondary school: $84.39 \%$ were from public schools and $15.61 \%$ from private ones, $47.07 \%$ were from High School including $21.35 \%$ vocational education. Adolescents reported on the highest education level obtained by either parent, there were as follows: $34 \%$ Master level, 26\% Bachelor's level, 18\% upper secondary general education, $14 \%$ upper secondary vocational education, $3 \%$ lower secondary education, $5 \%$ primary education. Parents were informed of the study and provided consent. Students completed self-report questionnaires during lesson time, with 
one hour reserved for completion. They were informed that participation was voluntary and that their responses were anonymous.

\section{Measures}

The PBS (Caprara et al., 2005) is a 16-item questionnaire rated on a 5-point Likert scale ranging from 1 (never/almost never true) to 5 (almost always/always true) that assesses four types of prosocial behaviors (sharing, helping, taking care of, and feeling empathic; 4 items per dimension). The translation from English to French by three independent researchers was made according to the recommendations of the International Test Commission (Hambleton, 2001).

The Basic Empathy Scale (BES) is a 20-item questionnaire rated on a 5-point Likert scale ranging from 1 (strongly disagree) to 5 (strongly agree) developed by Jolliffe and Farrington (2006) and adapted in French by Carré, Stefaniak, D'Ambrosio, Bensalah, and Besche-Richard (2013). It includes three dimensions: emotional contagion ( 6 items), cognitive empathy ( 8 items) and emotional disconnection (6 items). Its internal consistency was satisfactory in our sample (see Table 3).

\section{Analytic strategy}

Three sets of analyses were performed: (1) CFA for testing the original factor using Sample 1, (2) EFA for investigating the factor structure using Sample 2 and (3) CFA for testing the two-factor solution obtained by EFA using Sample 3 and Convergent Validity. In order to account for the ordered - categorical nature of the scale items, Weighted Least Square Means-Variance (WLSMV) and theta parameterization (for multiple group models) were performed using Mplus 7.3.

In total, missing data ranged from 0 to $3.75 \%$ across all samples. No missing data in Sample 1, 3.75\% in Sample 2 and 3.72\% in Sample 3. The percentage of missing values across the prosocial behaviors and empathy variables ranged between .57 and $6.63 \%$ in Sample 2 and .26 and $4.75 \%$ in Sample 3. In order to deal with the missing data, the WLSMV Multiple Imputations procedures were applied (Asparouhov \& Muthén, 2010).

Exploratory factor analysis (EFA) and factor analyses replication were performed using Sample 2. Concerning the EFA, the factor retention methods used included scree test and Velicer's MAP criteria (Velicer \& Jackson, 1990) using an oblique rotation. For the factor analyses replication, internal replicability analyses were performed, data was randomly split, and the same number of factors were extracted using the same rotation (Geomin) and extraction procedures in order to compare standardized factor loadings (Osborne \& Fitzpatrick, 2012).

Measurement Invariance across gender and grade through a series of multiple group models with progressively more stringent constraints were performed using Sample 3. A more constrained solution was rejected when: (a) the 
chi-square difference test $\left(\Delta X^{2}\right)$ had a probability lower than $.05^{1}$ (Byrne \& van de Vijver, 2010), (b) the decrease in the Comparative Fit Index criterion ( $\Delta C F I)$ was higher than $.01^{2}$ (Cheung \& Rensvold, 2002; Vandenberg \& Lance, 2000), (c) an increase in $\triangle$ RMSEA was higher than .015, indicating non-invariant loadings, thresholds or residuals (Chen, 2007).

\section{Results}

\section{CFA for testing the original four factor structure}

Confirmatory factor analyses of the original four factor structure yielded an acceptable fit $X^{2}=1026.661$ (98), $p<.001$, RMSEA $=.076$ [.072-.080], CFI $=.93$ and WRMR $=1.920$. The main concern of this original structure is the high factor correlations among latent variables ( $r=.87$ and .86 , respectively). Taking into consideration items similar wording and modification indices, 3 error covariances were added. Model fit was $X^{2}=806.488$ (95), $p<.001$, RMSEA $=.068$ [.036-.072], CFI $=.95$ and WRMR $=1.687$. Although a better fit was achieved, this resulted in an inflated estimate of the factors correlations (all above .85). In light of these issues, we decided to test a second - order model, this lead to an inadmissible parameter solution. Despite the good model fit, the discriminant validity is too low to accept the four-factor solution (Brown, 2015).

\section{EFA for investigating the factor structure}

Taking into account the exploratory factor analyses factor retention results and internal replicability analyses, we report the two-factor solution which provided much more statistically and theoretically coherent and interpretable factors than did the other solutions. EFA replicability suggested that 2 items $(2,11)$ failed to meet the initial criteria, i.e., the structural replication ${ }^{3}$; these two items were removed from further analyses.

\footnotetext{
${ }^{1} O$ wing to the WLSMV estimator used here, the change in $x^{2}$ and degrees of freedom cannot be calculated in a straightforward fashion. "The difference in chi-square values for two nested models using the [...] WLSMV chi-square values is not distributed as chi-square" (Muthén \& Muthén, 2017). Therefore, a scaling correction (DIFFTEST function) is used, of which only the $p$-value should be interpreted.

${ }^{2}$ The $\Delta X^{2}$ and $\Delta$ CFI may sometimes suggest different conclusions. Clear rules on how to proceed in such a situation are lacking (Byrne \& van de Vijver, 2010). Researchers can opt to describe the conclusions of both approaches or choose one over the other, based on the admissibility of the solution and examination of the modification indices.

${ }^{3}$ Specifically, looking at the factor loadings, item 2 "I share what I like with my friends" has the highest factor loading on Factor \#2 in the first analysis and on Factor \#1 in the second analysis; and item 11 "I easily lend money or other things" has the highest factor loading on Factor \#1 in the first analysis and on Factor \#2 in the second analysis. All other items have their strongest loading on congruent factors, so if we delete these two items, we would say that the factor structure of the scale meets the basic level of replication. The next step was to look at the squared differences in the factor loadings; these were within reasonable range (.0000-.0324), indicating that the largest difference between the standardized factor loadings is |.18|.
} 
Table 1. Fit indices for the different factor models of the PBS.

\begin{tabular}{lcccccc}
\hline Model & $x^{2}$ & df & RMSEA [90 Cl \%] & WRMR & CFI & TLI \\
\hline Two factor model & 700.369 & 76 & $.071[.066-.076]$ & 1.74 & .95 & .94 \\
Two factor model + 3 Cov. errors & 505.39 & 73 & $.060[.055-.065]$ & 1.46 & .97 & .96 \\
\hline
\end{tabular}

Notes: $x^{2}=$ Chi-square; $d f=$ degrees of freedom; RMSEA = Root Mean Square Error of Approximation; $\mathrm{Cl}=$ Confidence Interval; WRMR = Weighted Root Mean Square Residual; CFI = Comparative Fit Index; $\mathrm{TLI}=$ Tucker Lewis Index.

Cov. Error $=$ errors of items 1 and 3, 8 and 5, 12 and 8, are allowed to covary.

Table 2. Multiple-group confirmatory factor analyses of the two-factor +3 cov. error model for measurement and structure invariance across gender and grade $(N=1640)$.

\begin{tabular}{|c|c|c|c|c|c|c|c|c|c|}
\hline Model & $x^{2}(\mathrm{df})$ & RMSEA [90\% Cl] & WRMR & CFI & $\Delta \mathrm{x}^{2}$ & $\Delta \mathrm{df}$ & $p$ & $\Delta \mathrm{CFI}$ & $\begin{array}{c}\triangle \mathrm{RM}- \\
\mathrm{SEA}\end{array}$ \\
\hline \multicolumn{10}{|l|}{ MG-CFA Gender } \\
\hline $\begin{array}{l}\mathrm{M}_{1} \text {. Configural } \\
\text { invariance }\end{array}$ & 609.69 (146) & $.062[.057-.067]$ & 1.65 & .959 & - & - & - & - & \\
\hline $\begin{array}{l}M_{2} \cdot \text { Metric } \\
\text { invariance }\end{array}$ & $578.75(158)$ & $.057[.052-.062]$ & 1.67 & .963 & 9.63 & 12 & .65 & .004 & .005 \\
\hline $\begin{array}{l}\mathrm{M}_{3} \text {. Scalar } \\
\text { invariance }\end{array}$ & $677.61(198)$ & $.054[.050-.059]$ & 1.92 & .958 & 135.16 & 40 & $* * *$ & .005 & .003 \\
\hline $\begin{array}{l}\mathrm{M}_{3 \mathrm{a}} \text {. Partial } \\
\text { Scalar } \\
\text { invariance }\end{array}$ & $571.90(182)$ & $.051[.046-.056]$ & 1.73 & .966 & 31.25 & 24 & .15 & .003 & .006 \\
\hline $\begin{array}{l}\mathrm{M}_{4} . \text { Strict } \\
\text { invariance }\end{array}$ & $691.08(215)$ & $.052[.048-.056]$ & 2.02 & .958 & 48.28 & 17 & $* * *$ & -.008 & .001 \\
\hline \multicolumn{10}{|l|}{ MG-CFA Grade } \\
\hline $\begin{array}{c}\mathrm{M}_{1} \text {. Configural } \\
\text { invariance }\end{array}$ & $592.69(146)$ & $.061[.056-.066]$ & 1.61 & .965 & - & - & - & - & \\
\hline $\begin{array}{l}\mathrm{M}_{2} . \text { Metric } \\
\text { invariance }\end{array}$ & $584.49(158)$ & $.057[.052-.062]$ & 1.67 & .966 & 25.47 & 12 & $* *$ & .001 & .004 \\
\hline $\begin{array}{l}\mathrm{M}_{2} \text {. Metric invar- } \\
\text { iance (except } \\
\text { Item 6) }\end{array}$ & $568.13(157)$ & $.056[.052-.062]$ & 1.64 & .967 & 13.75 & 11 & .25 & .001 & .001 \\
\hline $\begin{array}{l}\mathrm{M}_{3} \text {. Scalar } \\
\text { invariance }\end{array}$ & $685.77(198)$ & $.055[.050-.059]$ & 1.92 & .961 & 137.98 & 40 & $* * *$ & .005 & .002 \\
\hline $\begin{array}{l}\mathrm{M}_{3 \mathrm{a}} . \text { Partial } \\
\text { Scalar } \\
\text { invariance }\end{array}$ & $569.29(180)$ & $.051[.047-.056]$ & 1.72 & .966 & 30.41 & 22 & .11 & .000 & .006 \\
\hline $\begin{array}{l}\mathrm{M}_{4} . \text { Strict } \\
\text { invariance }\end{array}$ & $800.16(215)$ & $.058[.053-.062]$ & 2.19 & .954 & 243.83 & 35 & $* * *$ & -.007 & .003 \\
\hline
\end{tabular}

Notes: $X^{2}=$ Chi-square; $\mathrm{df}=$ degrees of freedom; RMSEA = Root Mean Square Error of Approximation; $\mathrm{Cl}=$ Confidence Interval; WRMR = Weighted Root Mean Square Residual; $C F I=$ Comparative Fit Index. $\Delta \mathrm{x}^{2}=$ Delta Chi-square; $\Delta \mathrm{CFI}=$ Delta Comparative, $\triangle \mathrm{RMSEA}=$ Change in RMSEA. Fit Index. ${ }^{* *} p<.01$. $* * * p<.001$.

\section{CFA for testing the two factor structure and Convergent validity}

Confirmatory Factor Analyses using Sample 3 for testing the two-factor structure obtained by EFA was performed; due to similar wording and underlying motivation, three error covariances were added (see Table 1). This two factor-solution had an acceptable discriminant validity (see Table 3). This solution was tested to be invariant across gender and grade. The results confirmed partial measurement invariance for the two-factor model. All factor loadings (except 
Table 3. Descriptive statistics and correlations between PBS and BES dimensions.

\begin{tabular}{lccccccc}
\hline Measure & $M$ & SD & $\omega_{s}$ & 2 & 3 & 4 & 5 \\
\hline 1. PBS - Helping & 3.47 & .68 & .79 & $.79^{*}$ & $.35^{*}$ & $.41^{*}$ & $.34^{*}$ \\
2. PBS - Caring & 3.58 & .72 & .81 & - & $.60^{*}$ & $.55^{*}$ & $.52^{*}$ \\
3. BES - Emotional contagion & 3.52 & .82 & .70 & & - & $.68^{*}$ & $.54^{*}$ \\
4. BES - Cognitive empathy & 3.93 & .66 & .74 & & & - & $.50^{*}$ \\
5. BES - Emotional disconnection & 3.73 & .87 & .80 & & & & - \\
\hline
\end{tabular}

Note: $\omega$, = omega coefficient.

${ }^{*} p<.0001$.

item 6 across grade) proved to be invariant over gender and grade, and since at least two items for which all thresholds were invariant (Steinmetz, Schmidt, Tina-Booh, Wieczorek, \& Schwartz, 2009), meaningful latent mean comparison using the partially invariant factor are still possible, as it was suggested by Byrne, Shavelson, and Muthén (1989) that it "makes substantive sense to do so" ( $p$. 465). Fit indices are shown in Table 2. We labeled the first factor "Helping" (6 items; items 1, 3, 4, 6, 7, and 9) on which people who scored high reported being helpful and sharing with others. We labeled the second factor "Caring" (8 items; items 5, 8, 10, 12, 13, 14, 15, and 16) on which people who scored high were likely to feel responsibility for and concern about the welfare of others (see Supplementary material). The omega coefficients ${ }^{4}$ for the two dimensions were satisfactory and the two-factor solution did have an acceptable discriminant validity (see Table 3 ).

\section{Convergent validity}

Finally, we examined the convergent validity of the dimensions of the PBS and BES using CFA (i.e., latent correlations). The results revealed that Helping and Caring were positively associated to BES factors. The correlations between Caring and BES were higher than the correlations between Helping and BES (see Table 3). These results demonstrated convergent validity and were in line with those reported in the literature (Eisenberg, Eggum, \& Di Giunta, 2010).

\section{Discussion}

In the present study, we investigated the psychometric properties of the French version of the PBS in a large age range sample covering early and late adolescence. First, we tested the original four-factor structure, but decided not to retain this structure due to low discriminant validity. Secondly, Replication Analysis in Exploratory Factor Analysis suggested a two-factor solution. Third, Confirmatory Factor Analyses showed that the two-factor model had a good fit. The internal consistency of Helping and Caring were good. In addition, Helping and Caring

${ }^{4}$ Open source software JASP was used to calculate omega coefficients. 
were positively associated with empathy dimensions. This is in concordance with previous studies that reported a positive link between these two constructs (Eisenberg et al., 2010). Finally, our findings of partial measurement invariance across gender and grade confirm the relevance of the two-factor solution.

Further investigations with other samples (e.g., emerging adults and adults) compared to adolescents are needed in order to test whether the two-factor model is the best one across age, or whether this structure in two dimensions of prosocial behaviors is specific to the period of adolescence. Indeed, several theories on the development of social cognition posit that during adolescence important steps forward are made in social perspective-taking (Hoffman, 2001), thereby fostering prosocial behaviors (Eisenberg, Spinrad, \& Knafo-Noam, 2015). Meanwhile, the capacities of internalized / self-reflective other-oriented modes of reasoning observed across the 20 s and into the early 30 s might lead to a finer distinction of different dimensions of prosocial behaviors (Eisenberg, Hofer, Sulik, \& Liew, 2014). These considerations support our findings and other investigations across age from a developmental perspective.

\section{Disclosure statement}

No potential conflict of interest was reported by the authors.

\section{ORCID}

Alexia Carrizales (D) http://orcid.org/0000-0002-2985-6510

\section{References}

Alessandri, G., Kanacri, B. P. L., Eisenberg, N., Zuffianò, A., Milioni, M., Vecchione, M., \& Caprara, G. V. (2014). Prosociality during the transition from late adolescence to young adulthood:The role of effortful control and ego-resiliency. Personality and Social Psychology Bulletin, 40(11), 1451-1465. doi:10.1177/0146167214549321

Asparouhov, T., \& Muthén, B. (2010). Weighted least squares estimation with missing data. Mplus Technical Appendix, 1-10.

Batson, C. D. (1998). Altruism and prosocial behavior. In D. T. Gilbert, S. T. Fiske, \& G. Lindzey (Eds.), The handbook of social psychology (Vols. 1 and 2, 4th ed., pp. 282-316). New York, NY: McGraw-Hill.

Brown, T. A. (2015). Confirmatory factor analysis for applied research (2nd ed.). New York, NY: Guilford Publications.

Byrne, B. M., \& van de Vijver, F. J. R. (2010). Testing for measurement and structural equivalence in large-scale cross-cultural studies: Addressing the issue of nonequivalence. International Journal of Testing, 10(2), 107-132. doi:10.1080/15305051003637306

Byrne, B. M., Shavelson, R. J., \& Muthén, B. (1989). Testing for the equivalence of factor covariance and mean structures: The issue of partial measurement invariance. Psychological Bulletin, 105(3), 456-466. doi:10.1037/0033-2909.105.3.456

Calderón-Tena, C. O., Knight, G. P., \& Carlo, G. (2011). The socialization of prosocial behavioral tendencies among Mexican American adolescents: The role of familism 
values. Cultural Diversity \& Ethnic Minority Psychology, 17(1), 98-106. doi:10.1037/ a0021825

Caprara, G. V., Steca, P., Zelli, A., \& Capanna, C. (2005). A new scale for measuring adults' prosocialness. European Journal of Psychological Assessment, 21(2), 77-89. doi:10.1027/1015-5759.21.2.77

Carré, A., Stefaniak, N., D'Ambrosio, F., Bensalah, L., \& Besche-Richard, C. (2013). The basic empathy scale in adults (BES-A): Factor structure of a revised form. Psychological Assessment, 25(3), 679-691. doi:10.1037/a0032297

Chen, F. F. (2007). Sensitivity of goodness of fit indexes to lack of measurement invariance. Structural Equation Modeling: A Multidisciplinary Journal, 14(3), 464-504. doi:10.1080/10705510701301834

Cheung, G. W., \& Rensvold, R. B. (2002). Evaluating goodness-of-fit indexes for testing measurement invariance. Structural Equation Modeling: A Multidisciplinary Journal, 9(2), 233-255.

Eisenberg, N., Eggum, N. D., \& Di Giunta, L. (2010). Empathy-related responding: Associations with prosocial behavior, aggression, and intergroup relations. Social Issues and Policy Review, 4(1), 143-180. doi:10.1111/j.1751-2409.2010.01020

Eisenberg, N., Hofer, C., Sulik, M. J., \& Liew, J. (2014). The development of prosocial moral reasoning and a prosocial orientation in young adulthood: Concurrent and longitudinal correlates. Developmental Psychology, 50(1), 58-70. doi:10.1037/a0032990

Eisenberg, N., Spinrad, T. L., \& Knafo-Noam, A. (2015). Prosocial development. In M. E. Lamb, \& R. M. Lerner (Eds.), Handbook of child psychology and developmental science, Vol. 3: Socioemotional processes (7th ed., pp. 610-656). Hoboken, NJ: Wiley.

Gregory, A. M., Light-Häusermann, J. H., Rijsdijk, F., \& Eley, T. C. (2009). Behavioral genetic analyses of prosocial behavior in adolescents. Developmental Science, 12(1), 165-174. doi:10.1111/j.1467-7687.2008.00739

Hambleton, R. K. (2001). The next generation of the ITC test translation and adaptation guidelines. European Journal of Psychological Assessment, 17(3), 164172. doi:10.1027//1015-5759.17.3.164

Hoffman, M. L. (2001). Toward a comprehensive empathy-based theory of prosocial moral development. In A. C. Bohart \& D. J. Stipek (Eds.), Constructive \& destructive behavior: Implications for family, school, \& society (pp. 61-86). Washington, DC: American Psychological Association.

Jolliffe, D., \& Farrington, D. P. (2006). Development and validation of the basic empathy scale. Journal of Adolescence, 29(4), 589-611. doi:10.1016/j.adolescence.2005.08.010

Ladd, G. W., \& Profilet, S. M. (1996). The child behavior scale: A teacher-report measure of young children's aggressive, withdrawn, and prosocial behaviors. Developmental Psychology, 32(6), 1008-1024. doi:10.1037/0012-1649.32.6.1008

Muthén, L. K., \& Muthén, B. O. (2017). Mplus user's guide (8th ed.). Los Angeles, CA: Author. Retrieved July 13, 2017, from https://www.statmodel.com/ugexcerpts.shtml

Osborne, J. W., \& Fitzpatrick, D. C. (2012). replication analysis in exploratory factor analysis: What it is and why it makes your analysis better. Practical Assessment, Research \& Evaluation, 17(15), 1-8.

Padilla-Walker, L. M., \& Carlo, G. (2014). Prosocial development: A multidimensional approach. Oxford: Oxford University Press.

Rushton, J. P., Chrisjohn, R. D., \& Fekken, G. C. (1981). The altruistic personality and the self-report altruism scale. Personality and Individual Differences, 2(4), 293-302. doi:10.1016/0191-8869(81)90084-2

Steinmetz, H., Schmidt, P., Tina-Booh, A., Wieczorek, S., \& Schwartz, S. H. (2009). Testing measurement invariance using multigroup CFA: Differences between educational 
groups in human values measurement. Quality \& Quantity, 43(4), 599. doi:10.1007/ s11135-007-9143

Vandenberg, R. J., \& Lance, C. E. (2000). A review and synthesis of the measurement invariance literature: Suggestions, practices, and recommendations for organizational research. Organizational Research Methods, 3(1), 4-70. doi:10.1177/109442810031002 Velicer, W. F., \& Jackson, D. N. (1990). Component analysis versus common factor analysis: Some further observations. Multivariate Behavioral Research, 25(1), 97-114. doi:10.1207/s15327906mbr2501_12 